\title{
Foreword: extreme geohazards-a growing threat for a globally interconnected civilization
}

\author{
Hans-Peter Plag
}

Received: 6 May 2014/ Accepted: 6 May 2014/Published online: 16 May 2014

(C) Springer Science+Business Media Dordrecht 2014

Geohazards, such as earthquakes, landslides, volcano eruptions, tsunamis and floods, cause large and increasing loss of lives and properties. Most of these losses occur during highimpact, extreme events. The global and long-lasting societal and economic impacts of recent extreme events illustrate the scale of disasters that can be caused by geohazards. At the same time, the recent major geohazards are dwarfed by the largest geohazards that occurred during the last few millenniums. If such a mega hazard would occur today, the resulting disaster impacts would be unparalleled. The potential impacts on our civilization of any such rare event tend to be ignored in our planning of land use, infrastructure and services. Increasing global resilience and reducing the disasters induced by the occurrence of extreme hazards at an acceptable economic cost requires a solid-scientific understanding of the hazards.

A conference funded by the European Science Foundation brought together participants from four continents, and a wide range of disciplines for a review of the current understanding of high-impact geohazards and the challenges posed to the disaster risk management cycle (Plag and Marsh 2012a, b). The papers in this special issue provide samples of the range of topics addressed at the conference.

Major research has been undertaken to understand the causes and processes of geohazards, and advances in our knowledge of the hazardous areas have been achieved. Many measures required to prepare for, and adapt to, hazards have been developed, and several international programs are conducted informing governments, decision makers, and the general public on disaster risks, and ways to reduce these risks. Nevertheless, the loss of lives and properties through natural hazards, particularly geohazards, is rapidly increasing due to a growing population expanding into hazardous areas. Particularly in many areas with poverty and corruption, cities are rapidly sprawling into hazardous areas with too many people living and working in poorly constructed buildings. Today, far more people, property and potentially damaging infrastructure are in harm's way, and in many cases,

\section{H.-P. Plag ( $ه)$}

Mitigation and Adaptation Research Institute (MARI), Old Dominion University, Norfolk, VA 23529, USA

e-mail: hpplag@odu.edu 
neither the people nor the infrastructure are prepared for the hazardous events that will happen. Because of this, and because the interconnectivity of the global society increases, the direct and indirect consequences of extreme events will likely continue to increase. There is also a lack of models that would allow an assessment of potential disasters due to "domino effects," where an initial hazardous event triggers one or more natural or manmade hazards. With increasing potentially hazardous infrastructure built-in areas impacted by large geohazards, such domino effects can be expected to magnify future disasters. Likewise, in all societal sectors and for all natural and human-made hazards, the social construct of risk and vulnerability often biases risk assessments and leads to underappreciation, which then creates the possibility of "gray swans" that come as a surprise despite the fact that they could have been anticipated (Stein and Stein).

Concerning earthquakes, central information for society is where, when, how big and how much shaking will happen (Wong). Errors in any of these aspects result in forecast errors. The "Where?" tends to be biased toward previous events and thus misses future events that might occur in new locations; this is the case particularly for extreme events. What are needed to reduce this error are very long (not necessarily instrumental) records that capture the very rare events. The "When?" is again based on a too short time history and assumes that recurrence is predictable, which has to be doubted. Another problem is the choice of the area to be observed. There is a tendency to focus the location of recent events and thus to overlook other potential areas. The "How big?" and "How much?" depend on many assumptions and can change by $200-300 \%$ depending on the assumptions made. Our knowledge of the location and frequency of small to medium earthquakes, i.e., the more frequent events, is well developed, while there are significant gaps concerning the less frequent "M9" and larger events. A dedicated research effort is needed to improve our knowledge of the potential locations and frequency of extreme geohazards (for example, Liu and Harris, Bouhadad).

For submarine landslides, characterizing the frequency and magnitude of the hazard is difficult (Harbitz et al.). Even for past events, the "When?" is very hard to determine with any degree of accuracy. The disaster risk for submarine landslides is associated with the potential tsunami. For coastal landslides, the warning time for the near-field impact may be too short to take action. However, for larger submarine landslides, which can cause transocean tsunamis, a tsunami-warning system can significantly reduce the impact on human lives.

Volcanoes exhibit a wide range of hazards and probabilities. Santorini is the location of one of the biggest geohazard events in human history (Nomikou et al.). Today, Santorini is "inflating," has hot water at subsea cones, and exhibits newly increased seismic activity. With the help of remotely operated vehicles, the cones, circular domes, cracks and hydrothermal deposits are being studied. The Kolumbo subsea volcano to the Northeast of Santorini has active $\mathrm{CO} 2$ vents and activity impacting the biological environment. The ongoing activity warrants an integrated monitoring program.

Geohazards are not the only natural hazards with large uncertainties at the extreme end of the hazard spectrum and with potentially large impacts on humanity. Extreme droughts have caused major disasters, and in a time of climate change, droughts might decrease the already stressed food security with disasterous consequences. Characterizing droughts is a necessary step to better understand their impacts (Saghafian and Mehdikhani).

An example of infrastructure supporting disaster risk research and management is the Global Earthquake Model (GEM), which is motivated by an opportunity to integrate many relevant projects and to provide a common platform for an open discussion (Silva et al.). GEM encourages participation of local experts, and a multidisciplinary approach, which 
involves the private sector to increase funding, to ensure relevance and to serve many users.

For existing buildings, improved understanding of the risk often requires adaptation of the building. Particularly for heritage buildings, the economic impact of retrofitting can be significant, depending on building typology. A comparison of retrofit costs versus repair costs and the cost of rebuilding for different earthquakes can help to inform decisions on retrofitting (Bala).

A declaration agreed by the conference participants (http://www.geohazcop.org/ workshops/Sant_Feliu_2011/) identified specific actions that would address these scientific and societal challenges. Among others, a focused interdisciplinary research effort is needed to increase our understanding of the nature of the hazards and to improve the knowledge of potential locations, intensity and recurrence of extreme geohazards events globally. A sustained geohazard monitoring system is required to support with observations research on extreme geohazards, the detection of hazardous events, and disaster prevention, response and recovery. The importance of free data sharing in support of geohazard research and disaster risk reduction was underlined. A process for an integrated assessment of disaster risks due to geohazards and an authoritative scientific body [comparable to the Intergovernmental Panel on Climate Change (IPCC)] to communicate the results of the assessment was considered necessary in order to better inform decision makers. Research programs integrating natural and social sciences need to address all phases of the disaster risk management cycle. Developing a dedicated outreach and education program should be a priority in order to support a change in the citizens' and authorities' perception of the risks associated with major geohazards and to help recognize the challenges these hazards pose to society. Disseminating information on geohazards to relevant governmental bodies and citizens would allow for transparent decisions on where to build what and how, and where to reduce the vulnerability of existing buildings to future hazards. State-of-the-art products, actionable for policy makers are needed to support the development of legislation for risk reduction and planning for a safe built environment. Preparedness and mitigation measures need to be tailored to the specific local vulnerabilities, available resources and social, cultural and religious constraints. Fostering international collaboration with local experts would help regions with poorly developed governance mitigate the disaster risks. Particularly in developing countries, improvements of low-technology response and rescue capabilities would ensure that disaster-impacted population could be reached more rapidly.

\section{References}

Plag H-P, Marsh SH (2012a) Preparing for the extreme. GEO Newsl, No. 18. http://www.earthobservations. org/art_018_002.shtml

Plag H-P, Marsh SH (2012b) Workshop report-understanding extreme geohazards: the science of the disaster risk management cycle. European science foundation conference, November 28-December 1 2011, Sant Feliu de Guixols, Spain. http://www.geohazcop.org/workshops/Sant_Feliu_2011/ workshop_reporti.html 